NBER WORKING PAPER SERIES

\title{
OFFICIAL INTERVENTIONS AND THE FORWARD PREMIUM ANOMALY
}

\author{
Nelson C. Mark \\ Young-Kyu Moh \\ Working Paper 9948 \\ http://www.nber.org/papers/w9948
NATIONAL BUREAU OF ECONOMIC RESEARCH 1050 Massachusetts Avenue
Cambridge, MA 02138
August 2003

This paper was previously circulated under the title 'Continuous Time Market Dynamics, ARCH effects, and the Forward Premium Anomaly.' We thank Kathryn Dominguez for the Fed and Bundesbank intervention data. We have benefited from comments on the earlier draft by participants at the 2001 Econometric Society Summer Meetings, the 2001 Midwest Econometrics Group Meetings, and seminar participants at the University of Notre Dame, West Virginia University, University of Michigan, University of Kentucky, and Dartmouth College. The views expressed herein are those of the authors and not necessarily those of the National Bureau of Economic Research.

(C)2003 by Nelson C. Mark and Young-Kyu Moh. All rights reserved. Short sections of text, not to exceed two paragraphs, may be quoted without explicit permission provided that full credit, including $\odot$ notice, is given to the source. 
Official Interventions and the Forward Premium Anomaly

in the Dollar-DM Market

Nelson C. Mark and Young-Kyu Moh

NBER Working Paper No. 9948

August 2003, Revised September 2006

JEL No. F3

\title{
$\underline{\text { ABSTRACT }}$
}

This paper presents a model of exchange rate determination in which the forward premium anomaly emerges as the result of unanticipated central bank interventions in the foreign exchange market. Deviations from uncovered interest parity (UIP) therefore represent neither unexploited profit opportunities nor compensation for bearing risk. In simulations, the model generates a forward premium anomaly and matches several other notable features of US-German data. Additional empirical support is obtained from an analysis of Fed and Bundesbank interventions in the dollar-DM market where it is found that the forward premium anomaly intensifies during those times when a central bank intervenes.

\author{
Nelson Mark \\ Department of Economics and Econometrics \\ University of Notre Dame \\ Notre Dame, IN 46556 \\ and NBER \\ nmark@nd.edu \\ Young-Kyu Moh \\ Department of Economics \\ Tulane University \\ New Orleans, LA 70118 \\ ymoh@tulane.edu
}




\section{Introduction}

This paper studies an asset pricing anomaly in international finance known as the forward premium anomaly. This is the negative estimate of the slope in a regression of the future exchange rate return on the forward premium (which is equivalent to the interest rate differential by covered interest parity). Because uncovered interest parity (UIP) predicts the slope to be 1, negative estimates are considered anomalous. A good deal of work has been devoted to studying the forward premium anomaly but a satisfactory understanding of the phenomenon continues to elude researchers.

We propose and investigate the idea that the forward premium anomaly is caused by unanticipated central bank interventions in the foreign exchange market. In our setup, UIP holds almost all the time and is violated only at those instances when an intervention occurs. Our empirical work looks at the dollar-deutschemark rate and the dollar-yen rate where frequent central bank interventions have taken place during our sample period. Our emphasis on the surprise element of the interventions conforms to their irregular implementation and the absence of an official exchange-rate target. Since market participants cannot anticipate the interventions, the resulting deviations from UIP do not represent unexploited profit opportunities or compensation for bearing risk. Relatively few interventions are required to produce the anomaly. Interventions that cause violations of UIP in as little as 8 percent of the observations are sufficient to generate a forward premium anomaly that matches the data.

We pursue this idea because standard theories of the foreign-exchange risk premium that have been proposed to explain the forward premium anomaly have fared poorly when confronted by the data. Here, we note that empirical investigations of the intertemporal asset pricing model typically finds that the covariance between the exchange-rate return and consumption growth is insignificant and much too small to explain the data. Empirical assessments of the market CAPM come to similar conclusions with respect to the exchangerate and market portfolio returns. We mention also that there is little evidence to suggest that excess returns predicted by the forward premium anomaly are economically significant. In studies that employ survey expectations, the finding that the median expectation from the survey implies a subjective risk premium of zero implies either the implied profit opportunities are ignored by traders, the risk to return trade-off is sufficiently unattractive to exploit, or that traders do not perceive that the anomaly exists. ${ }^{1}$

\footnotetext{
${ }^{1}$ There is an extensive literature that attempts to understand the deviations from UIP. Engel (1996), Froot and Thaler (1990), Hodrick (1987), and Lewis(1995a) survey much of this literature. The findings from survey expectations were first established by Froot and Frankel (1989). More recently, Mark and $\mathrm{Wu}$ (1998) and Jeanne and Rose (2002) have studied the role of noise-trader risk in generating the forward premium anomaly. Chinn and Merideth (1998) and Alexius (2001) report fragmentary evidence that UIP holds over long horizons. Bansal and Dahlquist (2000) find that the forward premium anomaly is confined
} 
The paper begins by documenting features of the data that we seek to understand with the primary focus on the forward premium anomaly. The anomaly, which is present in both the dollar-deutschemark and dollar-yen data, is seen to intensifies when the monetary authorities intervene in the foreign exchange market. For the deutschemark, we find that the anomaly is present only during times of intervention. In nonintervention periods, the forward premium is still a biased predictor of the future exchange-rate return but the anomaly is not present. For the yen, the anomaly is present both during intervention and nonintervention periods but is much stronger during interventions.

To try to understand these aspects of the data, we build a simple model of exchange rate determination with central bank intervention. The basic model takes a continuous-time representation of UIP in which the log exchange rate can be solved as an exact nonlinear function of the interest differential. We then consider two alternative specifications of central bank interventions. The first is the Krugman (1992) intervention which occurs at the margins of an (informal) exchange rate band. UIP holds continuously and also in discretized observations if market participants have common and credible knowledge of the intervention rule. This is an uninteresting case to consider, however, since the model's predictions do not match the data. The more interesting case to consider is where interventions take the market by surprise as they would if plans are formulated in secret and conducted irregularly so that intervention rules are not known by the public. ${ }^{2}$ Thus, when interventions occur, they create an ephemeral but unexpected shift in the process that governs the interest differential. UIP is violated only during these intervention points. The time series is then composed of a mixture of observations (mostly) drawn from the UIP urn and from the 'UIP is violated' urn. When the future depreciation is regressed on the interest differential, the occasional violations create negative slope coefficient estimates.

The second specification allows the central bank to engage in inframarginal interventions. Here, there are two possible intervention bands-a firm outer band at which the authorities will conduct a Krugman intervention and an interior band at which the authorities may or may not intervene. Here again, we are primarily interested model predictions when the intervention rules are not known by market participants.

Related research includes Osterberg and Humpage (1992) and Baillie and Osterberg (1997b, 2000) who estimate the effects of intervention on deviations from UIP and LeBarron (1999), Sapp (2004) and Neely (2002) who study the effects of intervention on technical trading rule profits. These studies do not directly address the issue of the forward premium anomaly, however. Interventions that affect the deviation from UIP are necessary but not sufficient to explain the forward premium anomaly. The interventions must show a "lean against the

to G-7 economies and is absent in emerging market economies.

${ }^{2}$ Lewis (1995b) proposes an alternative to the target zone framework by modeling interventions to stabilize the exchange rate around a targeted level where the probability of intervention depends upon and is increasing in the gap between the current exchange rate and the target value. 
wind" pattern and be effective in adjusting the exchange rate.

Although it is not the primary focus of the paper, we also point out that our model provides a framework for understanding volatility clustering observed in financial data. While autoregressive conditional heteroskedasticity (ARCH) effects are commonly observed in financial returns data, little work has been done to understand its theoretical underpinnings. In our framework, endogenous $\mathrm{ARCH}$ effects emerge as the consequence of the market equilibrium. In the exchange rate solution, innovations to the equilibrium exchange rate depend on the squared interest differential which varies over time. As a result, the size of the conditional variance of the exchange rate return varies over time. ${ }^{3}$

The remainder of the paper is organized as follows. The next section presents the empirical regularities of the international finance data that we seek to understand. Section 2 presents our model of exchange-rate dynamics and central bank interventions. The quantitative assessment of the model is carried out by means of set of simulation experiments with parameter values set equal to their simulated method of moments (SMM) estimates. Section 3 discusses SMM estimation of model's parameters and the results of the simulation experiments are reported in section 4 . Section 5 offers some concluding comments. Derivations of the main results are contained in the appendix.

\section{The data}

The data are weekly observations of the spot exchange rate and one-week Eurocurrency rates for the U.S., Germany, and Japan. U.S.-German observations begin on 1/6/76 and extend through 12/25/98 which is one year before the deutschemark was irrevocably fixed to the euro. U.S.-Japanese observations extend from 1/6/77 through 12/27/02. Observations from $1 / 2 / 76$ through $12 / 27 / 85$ are Friday closings reported in the Harris Bank Weekly Review. Observations from $1 / 3 / 86$ through the end of the sample are Friday quotations from Datastream.

\subsection{Features of the data}

Let $s_{t}$ be the log dollar price of the foreign currency and $r_{t}$ be the corresponding 1-week "US-foreign" Eurocurrency rate differential. ${ }^{4}$ Table 1 reports several features of the data

\footnotetext{
${ }^{3}$ The state dependence of the volatility in equilibrium returns is a common feature in general equilibrium continuous time asset pricing e.g., Merton (1990). See also Den Haan and Spear (1998), who present a theory in which volatility clustering in real interest rates are generated by business-cycle dependent financial market frictions.

${ }^{4}$ Interest rates are stated in percent per annum. To conform to this normalization, the log exchange rates are multiplied by 5200 .
} 
that we seek to understand. We begin with the slope coefficient in the regression

$$
\Delta s_{t+1}=\alpha+\beta r_{t}+\epsilon_{t+1} .
$$

UIP predicts $\beta=1$. The literature refers to slope estimates that deviate from 1 as the "forward premium bias" and negative estimates as the "forward premium anomaly" Ȧs can be seen, the anomaly is present in both the dollar-deutschemark and dollar-yen data.

A Lagrange multiplier test for first-order $\mathrm{ARCH}$ in the regression residuals is highly significant, indicating that exchange rate excess returns exhibit volatility clustering. Fitting the conditional volatility in exchange rate excess returns to the $\operatorname{GARCH}(1,1)$ specification

$$
E_{t} \epsilon_{t+1}^{2}=h_{t}=\omega+\delta \epsilon_{t-1}^{2}+\gamma h_{t-1}
$$

yield estimates of $\delta$ and $\gamma$ that are statistically significant.

To examine the relationship between the conditional exchange rate return variance and the interest differential, we regress the conditional variance on the absolute value of the interest differential

$$
h_{t}=a_{0}+a_{1}\left|r_{t}\right|+v_{t} .
$$

The point estimates show that conditional exchange rate variance is increasing in the magnitude of the interest differential but the relationship is significant for the deutschemark but not for the yen.

Finally, Table 1 reports sample standard deviations $\left(\sigma_{\Delta s_{t}}, \sigma_{r}\right)$ and sample autocorrelations $\left(\rho_{\Delta s_{t}}, \rho_{r}\right)$. We observe that exchange rate returns are highly volatile and exhibit almost no serial correlation, the latter feature consistent with the popular random walk characterization of the log exchange rate. In contrast, the interest differential is highly serially correlated and is much smoother. Interest differential volatility is an order of magnitude smaller than exchange-rate return volatility. ${ }^{5}$

\subsection{Interventions and the forward-premium anomaly}

We now incorporate data on Fed/Bundesbank interventions in the dollar-deutschemark market and Fed/Bank of Japan interventions in the dollar-yen market to investigate the connection between foreign exchange interventions and the forward premium anomaly. ${ }^{6}$ The

\footnotetext{
${ }^{5}$ Whether the interest differential is $\mathrm{I}(1)$ or $\mathrm{I}(0)$ has been heavily tested by testing whether the spot and forward exchange rates are cointegrated. Evans and Lewis (1995) cannot reject that the interest differential is I(1) whereas Baillie and Bollerslev (1989), Choudhry (1999), Corbae et al. (1992), Hai et al (1997), Luintel and Paudyal (1998), Wu and Chen (1998) and Zivot (2000) do reject. Baillie and Bollerslev (1994) conclude that the interest differential has long-memory but is mean reverting with a fractional difference parameter between $1 / 2$ and 1 .

${ }^{6}$ We thank Kathryn Dominguez for the intervention data.
} 
German intervention data are daily indicators of whether the Bundesbank or the Fed had bought or sold dollars for deutschemark. The Japanese intervention data are analogously constructed for official dollar-yen transactions. From these intervention data, we define an intervention period to be one in which an intervention occurs within a window of time around Friday (the day that our exchange rate and interest rate data are sampled). We considered three intervention windows: i) a 5 day lead and lag window, ii) a 5 day lead window, and iii) a 5 day lag window. We then sort the observations according to whether they were drawn from an intervention period or from a nonintervention period and estimate (1) for each sample. The results are shown in Table 2.

For the dollar-DM market over the full sample, there is no forward premium anomaly in the absence of intervention. The point estimate of the slope slightly exceeds 1 during non-intervention periods when using the lead and lag window definition. The forward premium anomaly emerges during intervention periods. These results are robust to alternative intervention window definitions and the sub-sample analyses tell a similar story.

The results are a little less definitive for the dollar-yen market. Here, the forward premium anomaly is strong during intervention periods. The estimated slope is negative during nonintervention periods but it is much smaller in magnitude and is only marginally significantly less than 1. Similar findings are obtained in the subsample analyses. For the dollar-yen rate, the forward premium anomaly is seen to intensify during intervention periods.

What is the pattern for interventions? Are interventions more likely to occur when the interest differential is large? To address these questions, we consider a latent model where the central bank's propensity to intervene $y_{t}^{*}$, depends on the magnitude of the interest differential,

$$
y_{t}^{*}=\theta_{0}+\theta_{1}\left|r_{t}\right|+u_{t} .
$$

A central bank then intervenes $y_{t}=1$ (or does not $y_{t}=0$ ) if $y_{t}^{*}$ exceeds a threshold of 0 ,

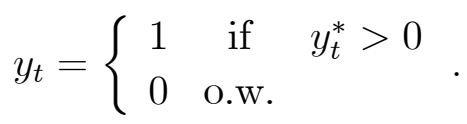

Probit estimation to the German data gives $\hat{\theta}_{0}=-0.726,(t=-9.056)$ and $\hat{\theta}_{1}=$ $0.208,(t=9.500)$. According to these estimates, the likelihood of an intervention increases with the size of the interest differential. Thus when the interest differential is large in magnitude, conditional exchange rate return volatility and the likelihood of an intervention is high. This pattern is consistent with the idea that the authorities engage in intervention to guide the exchange rate towards a target value (lean against the wind) and to lower market volatility (calm disorderly markets). ${ }^{7}$

\footnotetext{
${ }^{7}$ Baillie and Osterberg (1997a) and Dominguez (1998) find evidence that interventions are in part motivated to reduce market volatility.
} 
Again, we find differences between the German and Japanese data. Fitting the probit to the Japanese data yields $\hat{\theta}_{0}=0.046,(t=0.691)$ and $\hat{\theta}_{1}=-0.051,(t=-3.477)$. Here, the likelihood of interventions in the dollar-yen market is high when the interest differential is small. Looking at these results in conjunction with the insignificant relationship between exchange rate return volatility and the absolute value of the interest differential is consistent with the idea that many of the interventions undertaken by the Bank of Japan are done inframarginally.

To summarize, we find that the forward-premium anomaly is present in our data set. The anomaly is present in the dollar-deutschemark market only when monetary authorities intervene. While the anomaly is always present in the dollar-yen market, it intensifies when the authorities intervene. Weekly exchange-rate excess returns exhibit ARCH effects, are nearly serially uncorrelated and are much more volatile than the relatively persistent interest differential. The probit estimates for the German data suggests that interventions can be modeled as occurring at the margins whereas the probits for the Japanese data are suggest that inframarginal interventions may be more appropriate.

\section{Modeling interventions and the forward premium anomaly}

In this section, we present a simple model of the foreign exchange market to explain features of the data discussed above.

\subsection{Marginal interventions}

Let $r(t)$ be the instantaneous yield differential between domestic and foreign-currency denominated debt instruments with identical default risk and let $s(t)$ be the instantaneous exchange rate. In continuous time, UIP is the first-order stochastic differential equation

$$
\mathrm{E}_{t}[d s(t)]=r(t) d t
$$

where $\mathrm{E}_{t}(\cdot)$ is the expectation conditional on information available at instant $t$ and $d s(t)$ is the forward differential of $s(t)$.

To obtain an explicit solution, we make a standard assumption in the target-zone literature and assume that $r(t)$ follows a regulated Brownian motion constrained to lie within bands $[\underline{r}, \bar{r}]$ where $\underline{r}<\bar{r}$. The existence of an informal set of bands (known to central bankers if not the public) is motivated by the probit results in the previous section. When $r(t)$ lies strictly within the bands, it evolves according to the Brownian motion,

$$
d r(t)=\sigma_{r} d z(t),
$$


where $d z(t)$ is a standard Wiener process and $\sigma_{r}$ is the weekly volatility in $d r(t)$. The regulated Brownian motion generates high persistence in the interest differential with bounded variance. To simplify the exposition, we assume that the reflecting barriers are symmetric $(\underline{r}=-\bar{r}) \cdot{ }^{8}$

This is a variant of the Krugman (1992) target zone model. The main difference is that Krugman's model is based on a monetary model of the exchange rate that assumes UIP but also relies on several additional relations (such as a stable money demand functions and purchasing power parity). In his model, the monetary authorities intervene by adjusting a set of vaguely defined monetary fundamentals whereas in our specification, intervention is accomplished by adjusting the interest differential. Marginal interventions occur whenever $r(t)=\bar{r}$ or $r(t)=-\bar{r}$ to prevent $r(t)$ from exiting the bands. When $r(t)$ lies within the bands, we think of the authorities as focusing on domestic objectives so that the interest differential, which is subject to many different sources of shocks, evolves randomly. ${ }^{9}$

(1) and (3) admit the family of solutions,

$$
s(t)=A+B r(t)+\frac{r^{3}(t)}{3 \sigma_{r}^{2}},
$$

where $A$ and $B$ are coefficients to be determined by auxiliary conditions. $A$ depends on initial conditions and on currency units so without loss of generality, we set $A=0$. Figure 1 shows solutions for alternative values of $B$. The nonlinearity in the exchange rate function with respect to the interest differential is qualitatively similar to Krugman's S-shape relationship between the exchange rate and the 'fundamentals.'

Using Ito's lemma to take the total differential of (3) gives the instantaneous depreciation

$$
d s(t)=r(t) d t+\left(B+\frac{r^{2}(t)}{\sigma_{r}^{2}}\right) \sigma_{r} d z(t)
$$

${ }^{8}$ Under band symmetry, the unconditional mean of $r(t)$ is 0 . The appendix shows how band symmetry can be relaxed. Recent research has exploited similar nonlinear models to study exchange rates [Michael, Nobay and Peel (1997), Kilian and Taylor (2001)]. Since interest differentials and exchange rates are functionally related, it is natural to also consider nonlinear adjustment in the interest differential. We note also that (2) is consistent with individual interest rate dynamics that evolve according to $d i(t)=\sigma_{1} d z_{1}(t)$ when $i \in[\underline{i}, \bar{l}]$ and $d i^{*}(t)=\sigma_{2} d z_{2}(t)$ when $i^{*} \in\left[\underline{i}^{*}, \bar{\imath}^{*}\right]$, where $d z_{t}(t)=\rho d z_{1}(t)+\sqrt{1-\rho^{2}} d w(t)$ and $d w(t)$ and $d z_{1}(t)$ are independent standard Wiener processes. Then we have $d r(t)=d i(t)-d i^{*}(t)=\sigma_{r} d z(t)$ where $\sigma_{r}=\sqrt{\left(\sigma_{1}-\rho \sigma_{2}\right)^{2}+\sigma_{2}^{2}\left(1-\rho^{2}\right)}$, and $d z(t)$ is a standard Wiener process. If we set $\underline{i}=\underline{i}^{*}=0$, then we have $\bar{r}=\bar{\imath}$ and $\underline{r}=-\bar{\imath}^{*}$. In any finite sample, however, we may not have very many realizations of the event $\left\{i_{t}=\bar{\imath} \cap i_{t}^{*}=\underline{i}^{*}\right\}$ or of the event $\left\{i_{t}=\underline{i} \cap i_{t}^{*}=\bar{\imath}^{*}\right\}$ so the standard error on the estimate of $\bar{r}$ is likely to be quite large.

${ }^{9}$ The idea that a monetary policy rule that depends on the exchange rate explains violations of UIP was also examined by McCallum (1994). In his analysis, the authorities set the interest differential in response to the currency depreciation rate. 
UIP holds regardless of the value of $B$ as long as $r(t)$ lies strictly within the band. This is because $d z(t) \sim N(0, d t)$ so that taking expectations on both sides of $(4)$, gives $\mathrm{E}_{t}[d s(t)]=$ $r(t) .{ }^{10}$ If market participants know the intervention rule, then maintaining UIP at the instant of intervention requires

$$
B=-\bar{r}^{2} / \sigma_{r}^{2} .
$$

To see why, suppose $r$ hits the upper band $\bar{r}$. At this instant, the authorities intervene to prevent an exit from the band which causes the distribution of $d z(t)$ to become right truncated at zero with conditional mean $\mathrm{E}[d z(t) \mid r(t)=\bar{r}] \simeq-0.80$. The restriction on $B$ ensures that the composite error term in (4) vanishes when $r(t)=\bar{r}$.

We also point out that the instantaneous conditional variance of the composite error term in (4), $\left(B+r^{2}(t) / \sigma_{r}^{2}\right)^{2} \sigma_{r}^{2} d t$, depends on the interest differential. The model generates $\mathrm{ARCH}$ effects in exchange rate excess returns because this conditional variance will change as $r(t)$ varies in size.

Because UIP does not hold in the data, the restriction (5) is not a specification that we take as a serious model for understanding the data. Instead, our primary interest will focus on leaving $B$ as a free parameter which we will estimate from the data. When agents do not properly anticipate interventions, $B \neq-\bar{r}^{2} / \sigma_{r}^{2}{ }^{11}$ It follows that conditional on being at the upper band (say), market participants believe ex ante that UIP will hold whereas in truth, it is violated. At this instant, participant's subjective conditional expectation of $d s(t)-r(t)$ will deviate from the true expectation by the right hand side of

$$
\mathrm{E}[d s(t) \mid r(t)=\bar{r}]-\bar{r} d t=-\left(B+\frac{\bar{r}^{2}}{\sigma_{r}^{2}}\right) \sigma_{r}(0.8) .
$$

\footnotetext{
${ }^{10}$ We can entertain alternative intervention rules suggested in the target-zone literature. For example, suppose participants believe that the authorities will intervene by setting the interest differential to 0 when one of the bands is hit, as in Flood and Garber (1991). Then maintaining UIP during instants of intervention gives $B=-\frac{\bar{r}^{2}}{3 \sigma_{r}^{2}}$, where the coefficient on $r$ scaled down by $1 / 3$. If the intervention rule lacks full credibility in the sense of Bertola-Caballero (1992), the coefficient is scaled down even further. In this setup, we begin with an initial band $[-\bar{r}, \bar{r}]$ of size $b=2 \bar{r}$. Suppose that when the upper band $\bar{r}$ is touched, there is a probability $p$ that the authorities will realign instead of defending the initial band. $1-p$ is the probability that they defend the initial band. If realignment occurs, the authorities establish a new band where the old upper band $\bar{r}$ is now the lower band and the new upper band is $\bar{r}+b$ and they place the interest differential in the middle of the new band. If defense takes place, the authorities place the interest differential back at the midpoint of the band as in the Flood-Garber intervention. In this environment, maintenance of UIP during instants of defense or realignments gives $B=\left[\frac{(8 p-1) \bar{r}^{2}}{3 \sigma_{r}^{2}}\right]$.

${ }^{11}$ An alternative strategy for incorporating this idea would be to build a model of nonsystematic interventions that are sufficiently irregular that agents maintain diffuse priors over the interventions. Dominguez (2003) provides a narrative account of Fed intervention policy and evidence on market discovery of intervention episodes. See also Klein and Lewis (1993) who present a model in which market participants update their prior probabilities about the interventions as Bayesian and learn about the bands over time. An analysis of learning is beyond the scope of this paper.
} 
Notice that in order for the forward-premium anomaly to emerge from stabilizing (leaning against the wind) interventions, the interest differential must appear negatively correlated with the future depreciation. This will be the case if $B>-\bar{r}^{2} / \sigma_{r}^{2}$. We will refer to this as the occasional violation (of UIP) specification because UIP holds except at finitely many instants.

\subsubsection{Properties of discretized observations}

Since our quantitative investigation of the model will involve discretizing the continuous time observations to conform with the weekly data set, we discuss some theoretical properties of the discretized observations. We begin by integrating (4) to obtain $\int_{0}^{1} d s(t)=s(1)-s(0)$ and rearranging to obtain

$$
s(1)-s(0)=r(0)[1+\epsilon(1)]+v(1)
$$

where

$$
\begin{aligned}
\epsilon(1)= & \frac{1}{\sigma_{r}}\left[r(0)-2 \sigma_{r} z(0)\right] \underbrace{\int_{0}^{1} d z(t)}_{(i)}+2 \underbrace{\int_{0}^{1} z(t) d z(t)}_{(i i)} \\
v(1)= & \sigma_{r} z^{2}(0) \underbrace{\int_{0}^{1} d z(t)}_{(i)}+\sigma_{r} \underbrace{\int_{0}^{1} z(t) d t}_{(i i i)}-2 \sigma_{r} z(0) \underbrace{\int_{0}^{1} z(t) d z(t)}_{(i i)} \\
& +\sigma_{r} \underbrace{\int_{0}^{1} z^{2}(t) d z(t)}_{(i v)}-\sigma_{r} z(0)+B \sigma_{r} \underbrace{\int_{0}^{1} d z(t)}_{(i)} .
\end{aligned}
$$

That ARCH effects are preserved can be seen by the interaction term $r(0) \epsilon(1)$. It is also interesting to note that (7) conforms to the "big-news" representation of Schotman et al. (1997). Letting $\epsilon_{t+1}$ and $v_{t+1}$ be conditionally zero-mean innovations, they put forth the parametric representation of UIP

$$
s_{t+1}-s_{t}=r_{t}\left(1+\epsilon_{t+1}\right)+v_{t+1},
$$

calling the multiplicative error $r_{t} \epsilon_{t+1}$ "big news" and the additive error $v_{t+1}$ "regular news." They concluded that the forward premium anomaly may be a statistical artifact resulting from poor sampling properties of the OLS estimator when the observations are generated by this representation and where the interest differential is also drawn from a heavy-tailed distribution. $^{12}$

\footnotetext{
${ }^{12}$ Big news is not the only ingredient in the Schotman et al. story of poor small sample properties of
} 
From (7)-(9) the distribution of the big news is seen to be leptokurtotic. ARCH effects are preserved under discretization as seen by the dependence of the conditional variance of the big news component $\mathrm{E}_{0}\left[r(0)^{2} \epsilon(1)^{2}\right]$ on $r(0)$. Several of the error components in (8) and (9) have more familiar representations. The term labeled $(i)$ is $\int_{0}^{1} d z(t) \sim N(0,1)$, the term labeled $(i i)$ is $\int_{0}^{1} z(t) d z(t) \sim \chi^{2}(1)-1$, which is skewed, and the term labeled $(i i i)$ is $\int_{0}^{1} z(t) d t \sim N\left(0, \frac{1}{3}\right)$. The term labeled $(i v)$ is $\int_{0}^{1} z^{2}(t) d z(t)$ which is nonstandard. We investigated its properties by simulation and find it to be zero-meaned with a symmetrically leptokurtotic distribution (coefficient of excess kurtosis equal to 86.56).

In conforming to our earlier analysis, we are interested in regressing the weekly depreciation on the 1-week interest differential, $R(0,1)$, and not on the instantaneous return differential $r(0)$. To do this, we appeal to the expectations hypothesis of the term structure of interest rates, $R(0,1)=\mathrm{E}_{t}\left(\int_{0}^{1} r(u) d u\right)=r(0) \int_{0}^{1} d u=r(0)$, the discretized representation corresponds to the regression run on the data even though $r(0)$ is the instantaneous yield.

\subsection{Inframarginal interventions}

Because the Bank of Japan evidently conducts interventions inframarginally, we consider a modification of the model for interventions of this type. Here, we assume that there is a "hard" outer band $[-\bar{r}, \bar{r}]$ which if reached will trigger a Krugman-type intervention with probability 1 . There is also an inframarginal band $\left[-\bar{r}_{1}, \bar{r}_{1}\right]$ where $\left|\bar{r}_{1}\right|<|\bar{r}|$ which if reached from 'within' will elicit an intervention with some probability $p<1$. The bands are illustrated in Figure 2.

Figure 2. Soft inframarginal and hard outer bands.

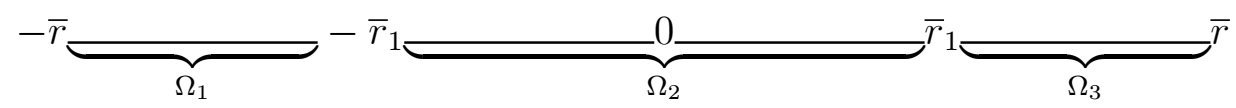

The following discussion pertains to the upper bands. The treatment of the symmetric lower bands should be obvious. As $r$ approaches $\bar{r}_{1}$ from below, the authorities engage in a variant of Bertola-Cabellero intervention. If an intervention occurs, the interest differential is set to $\alpha_{1} \bar{r}_{1}$, where $0<\alpha_{1}<1$. If the inframarginal band is "abandoned," the authorities

OLS. They also assume that the interest differential is drawn from a leptokurtotic distribution. In work along similar lines, Baillie and Bollerslev (2000) demonstrate that the inter 90-percentile range of the OLS empirical distribution from regressing the exchange rate return on the interest differential is $(-5.14,10.9)$ when the conditional volatility in the interest differential follows their calibrated fractionally integrated generalized ARCH process. 
set the interest differential to $\alpha_{2} \bar{r}_{1}$, where $\alpha_{2}>1$ This two-sided discrete change in $r$ allows identification of the parameters parameters under common knowledge of the intervention rule. Since the properties of the model will be investigated by simulation, the empirical predictions from the model we can set $\alpha_{2}$ infinitesimally greater than 1 to approximate what would happen if there is no action by the authorities if they decline to intervene at $\bar{r}_{1}$.

There are two solutions depending on whether the interest differential lies inside (region $\Omega_{3}$ ) or outside (region $\Omega_{2}$ ) of the inframarginal band. They are

$$
s(t)=\left\{\begin{array}{cl}
G_{1}(r)=B_{1} r+\frac{r^{3}}{3 \sigma^{2}} & \text { if } r \in \Omega_{3} \\
G_{2}(r)=A_{2}+B_{2} r+\frac{r^{3}}{3 \sigma^{2}} & \text { if } r \in \Omega_{2}
\end{array},\right.
$$

where

$$
\begin{aligned}
& B_{1}=-\left[\frac{p\left(\alpha_{1}^{3}-\alpha_{2}^{3}\right)-1+\alpha_{2}^{3}}{p\left(\alpha_{1}-\alpha_{2}\right)-1+\alpha_{2}}\right] \frac{\bar{r}_{1}^{2}}{3 \sigma^{2}}, \\
& B_{2}=-\left(\frac{\bar{r}^{2}}{\sigma^{2}}\right), \\
& A_{2}=\left(B_{1}-B_{2}\right) \alpha_{2} \bar{r}_{1} .
\end{aligned}
$$

$B_{2}$ is obtained from the marginal intervention solution and $A_{2}$ glues the exchange rate path from region $\Omega_{1}$ to $\Omega_{2}$ to eliminate jumps. The solution is illustrated in Figure 3 for $\alpha_{1}=0.99, \alpha_{2}=1.001, p=0.3,\left|\bar{r}_{1}\right|=0.05$ and $|\bar{r}|=0.10$.

When the intervention rule is not known by market participants, violations of UIP will occur at each of the intervention points. Treatment of this case proceeds as discussed above with a single solution and using $B$ estimated from the data.

\section{Simulated method of moments estimation of the model parameters}

We estimate the parameters $\left(\bar{r}, \sigma_{r}\right)$ of the interest rate processes for the marginal interventions model using the simulated method of moments (SMM). ${ }^{13}$ To do so, we divide each of the $T$ weekly observations into $N$ subintervals, of length $\delta_{N}=1 / N \simeq d t$, and use Euler's method to approximate the continuous-time model

$$
r_{j}=r_{j-1}+\sigma_{r} \epsilon_{j} \sqrt{\delta_{N}}
$$

where $j=1, \ldots, N T, \epsilon_{j} \stackrel{i i d}{\sim} N(0,1)$, and $\sigma_{r}$ is the weekly standard deviation of the instantaneous rate of return differential $r(t)$. The parameters $\bar{r}$ and $\sigma_{r}$ are chosen such that

\footnotetext{
${ }^{13}$ Lee and Ingram (1991), Duffie and Singleton (1993).
} 
the implied moments generated from simulations of (10) minimize a measure of quadratic distance between the set of simulated and sample moments.

Using the 3 moments $\mathrm{E}\left(\Delta r_{t}, \Delta r_{t}^{2}, r_{t} r_{t-1}\right)$, for the U.S.-German case we obtain estimated values of $\hat{\sigma}_{r}=0.576$ (s.e. $\left.=0.070\right), \hat{\bar{r}}=5.632$ (s.e. $=0.643$ ). The J-statistic for the chi-square test of the over identifying restrictions is 0.008 which with one degree of freedom gives a p-value of 0.930 and is not rejected by the data. For the U.S.-Japanese case, we obtain $\hat{\sigma}_{r}=0.817$ (s.e. $\left.=0.135\right), \hat{\bar{r}}=5.221$ (s.e. $=0.531$ ). The J-statistic for the chi-square test of the over identifying restrictions is 0.066 which with one degree of freedom gives a p-value of 0.797 .

In the simulation work conducted below, the UIP model uses the parameter estimates $\hat{\bar{r}}$ and $\hat{\sigma}_{r}$ and assumes $B=-\hat{\bar{r}}^{2} / \hat{\sigma}_{r}^{2}$. Simulations of the occasional violations model will not impose this condition but will employ values of $B$ estimated directly from the data. To do this, we apply the Euler method to the exchange rate (3) and do SMM estimation using the moments $\left(\mathrm{E} \Delta s_{t}, \mathrm{E} \Delta s_{t}^{2}, \mathrm{E} \Delta s_{t} r_{t-1}\right)$. For the U.S. German case, we obtain $\hat{B}=102$ (s.e. $=6.11)$. The positive point estimate is evidence against the hypothesis that UIP holds at intervention points. Although carrying out classical hypothesis tests of the model are not our primary interest, we note that tests of the over identifying restrictions are somewhat unfavorable to the model $(\mathrm{J}=43$, p-value $=0.00)$. For the U.S.-Japanese case, we obtain $\widehat{B}=98.4$ (s.e. $=4.94)$ with $\mathrm{J}=104$, p-value $=0.00$.

Calibration of the inframarginal intervention model will achieved using less formal methods.

\section{Quantitative properties of the model}

We now investigate the quantitative ability for the model to account for the data. We conduct 5000 model simulations with the calibrated model. Each simulation begins with a realization of the Euler-approximated continuous-time interest differential and exchange rate with the weekly time interval divided into 84 subintervals. The initial value of the interest differential is drawn from the uniform distribution with support $[-\bar{r}, \bar{r}]$. We then draw observations at weekly intervals that conforms to the number of data points in the sample. The simulated observations are then employed to calculate the statistics that were used to characterize the data.

\subsection{Marginal interventions}

Table 3 shows median values of the statistic in question and the inter-95 percentile range (in parentheses) for the model generated under marginal interventions. The model for the interest differential is seen to do a good job of matching the sample moments. To 
benchmark our findings, we also show results, under the UIP heading, generated under common knowledge of the intervention rule. This model is counterfactual in that it does not generate a forward-premium bias, the conditional variance of exchange-rate returns shows the wrong relationship with the size of the interest differential, and the exchange rate return is not volatile enough.

When UIP is occasionally violated, the model generates a pronounced forward premium anomaly. For both the deutschemark and the yen, the inter-95-percentile range of $\widehat{\beta}$ lies below the point estimate from the data. We observe strong ARCH effects with the inter 95-percentile of the LM statistic distribution lies above the point estimate from the data. The implied GARCH $(1,1)$ process matches the data for the deutschemark but misses for the yen (implied $\delta$ is too small and implied $\gamma$ is too large). The model matches the volatility in the exchange rate return and the interest differential, which are vastly different from each other. The simulations also capture the strong positive relation between the conditional variance $h_{t+1}$ of the exchange-rate return and the magnitude of the interest differential $\left|r_{t}\right|$ for the deutschemark and reflects the more tenuous relationship between these variables for the yen. ${ }^{14}$

How frequently do these violations occur in producing these results? Based upon the dollar-deutschemark estimated model and a weekly sampling interval of the observations, the unconditional probability of touching either of the bands is 0.081 . Over the course of a sample of 23 years, this amounts to interventions in approximately 98 out of the total 1200 weekly observations.

\subsection{Inframarginal interventions}

The parameters to be set are $\bar{r}, \bar{r}_{1}, p, \alpha_{1}$, and $\alpha_{2}$. For the dollar-DM market, the maximal interest differential observed is $12.31 \%$, which leads us to set $\bar{r}=12$. Since 86 percent of the interventions occurred while $|r| \leq 6 \%$. These 'inframarginal' interventions accounted for 34.5 percent of the weekly observations leading us to set $\bar{r}_{1}=6$ and $p=0.345$. Analogous calculations for Japan lead us to set $\bar{r}=12, \bar{r}_{1}=6, p=0.4$. We set $\alpha_{1}=0.99$ and $\alpha_{2}$ $=1.001$ for both markets.

Simulation results are displayed in Table 4. To benchmark our findings, the results under the UIP heading are generated under common knowledge of the intervention rule. When UIP holds, the GARCH model again looks reasonable but overall, the implied volatility of exchange rate returns is too small. The relation between conditional exchange rate

\footnotetext{
${ }^{14}$ The heightened volatility associated with large U.S.-German interest differentials and intervention points predicted by the occasional violations model is consistent with empirical findings of Dominguez (1989) and others who find that heightened exchange rate volatility shortly following central bank interventions.
} 
volatility and the interest differential doesn't match the data for the dollar-DM rate but provides a better match for the dollar-yen rate.

When interventions are surprise events, the model matches the forward premium anomaly for both the DM and yen rates. This model generates unconditional volatility of exchange rate returns that are close to the data. The implied GARCH $(1,1)$ process does not match the yen volatility, however.

\subsection{Comparison of marginal and inframarginal interventions with occasional violations}

When interventions are surprises, both specifications of interventions are able to explain the forward premium anomaly. The anomaly is slightly attenuated under inframarginal interventions. Both specifications are able to qualitatively explain the main features of the data. In general, the implied difference in the properties of the observations between the marginal and inframarginal intervention models is not great. The implied $\operatorname{GARCH}(1,1)$ structure of exchange return excess volatility is also very similar across the models. Inframarginal interventions create somewhat higher unconditional exchange rate volatility. The implied relationship between exchange rate volatility and the interest differential in the inframarginal model is stronger and more systematic than that found in the data.

\section{Conclusion}

The forward premium anomaly has long confounded researchers. The dominant approaches taken in the literature towards understanding this phenomenon are either that the anomaly is induced by a time-varying foreign exchange risk premium or that the anomaly signifies some sort of market inefficiency. Neither approach, however, has very high explanatory power.

The explanation offered in this paper, that the anomaly is induced by unanticipated central bank interventions in foreign exchange, is new. We put forth a simple model in which the forward premium anomaly emerges as a result of unanticipated central bank interventions in the foreign exchange market. In this model, the violations to UIP do not reflect unexploited profit opportunities or systematic risk. By this reasoning, the forward premium anomaly represents neither unexploited profit opportunities nor compensation for risk bearing. Instead, it arises due to momentary model misspecifications at the time of intervention. A direct analysis of the data and simulations of the theoretical model provide empirical support for this explanation. The data shows that the forward premium anomaly intensifies during periods in which central banks are intervening which suggests that the interventions themselves may be the source of the anomaly. Simulations of the model show 
that it is able to quantitatively match the foreign premium anomaly as well as many other notable properties of the data. 
Table 1: Features of weekly exchange rate and euro-deposit rates

\begin{tabular}{|c|c|c|}
\hline & US-Germany & US-Japan \\
\hline \multicolumn{3}{|l|}{$\Delta s_{t+1}=\alpha+\beta r_{t}+\epsilon_{t+1}$} \\
\hline$\widehat{\beta}$ & -0.693 & -2.498 \\
\hline t-ratio $(\beta=1)$ & -2.024 & -4.920 \\
\hline LM test for $\operatorname{ARCH}(1): \chi^{2}(1)$ & 281.832 & 135.812 \\
\hline \multicolumn{3}{|l|}{$\operatorname{GARCH}(1,1): h_{t+1}=\omega+\delta \epsilon_{t}^{2}+\gamma h_{t}$} \\
\hline$\widehat{\delta}$ & 0.080 & 0.129 \\
\hline (ase) & $(0.014)$ & $(0.016)$ \\
\hline$\widehat{\gamma}$ & 0.914 & 0.682 \\
\hline (ase) & $(0.035)$ & $(0.029)$ \\
\hline \multicolumn{3}{|l|}{$h_{t+1}=a_{0}+a_{1}\left|r_{t}\right|+v_{t}$} \\
\hline$\widehat{a}_{1}$ & 432.300 & 47.203 \\
\hline t-ratio & $(8.327)$ & $(1.046)$ \\
\hline$R^{2}$ & 0.771 & 0.760 \\
\hline \multicolumn{3}{|l|}{ Exchange Rate } \\
\hline$\sigma_{\Delta s_{t}}$ & 79.063 & 83.525 \\
\hline$\rho_{\Delta s_{t}}(1)$ & 0.001 & -0.001 \\
\hline \multicolumn{3}{|l|}{ Interest Differential } \\
\hline$\sigma_{r}$ & 3.230 & 3.062 \\
\hline$\rho_{r}(1)$ & 0.985 & 0.966 \\
\hline$\rho_{r}(12)$ & 0.847 & 0.731 \\
\hline$\rho_{r}(24)$ & 0.789 & 0.543 \\
\hline
\end{tabular}

Notes: Log exchange rates multiplied by 5200 . Interest rate differential in percent per year. 
Table 2. Interventions and the forward premium anomaly

Deutschemark

\begin{tabular}{|c|c|c|c|c|c|c|}
\hline & \multicolumn{3}{|c|}{ Interventions } & \multicolumn{3}{|c|}{ No Interventions } \\
\hline & Lead/Lag & Lead & Lag & Lead/Lag & Lead & Lag \\
\hline \multicolumn{7}{|c|}{ Sample: 1977-1998 } \\
\hline $\bar{\beta}$ & -1.591 & -2.183 & -2.346 & 1.195 & 1.130 & 1.601 \\
\hline t-ratio & -2.110 & -2.255 & -2.380 & 0.147 & 0.111 & 0.506 \\
\hline Nobs & 632 & 553 & 552 & 520 & 599 & 600 \\
\hline \multicolumn{7}{|c|}{ Sample: 1977-1991 } \\
\hline $\bar{\beta}$ & -2.179 & -2.788 & -2.340 & 0.242 & 0.363 & 0.894 \\
\hline t-ratio & -2.112 & -2.252 & -2.042 & -0.317 & -0.329 & -0.053 \\
\hline Nobs & 592 & 531 & 530 & 194 & 255 & 256 \\
\hline \multicolumn{7}{|c|}{ Sample: 1992-1998 } \\
\hline $\bar{\beta}$ & -4.198 & -7.630 & -3.896 & 0.711 & 0.652 & 0.671 \\
\hline t-ratio & -1.377 & -2.011 & -0.879 & -0.184 & -0.231 & -0.220 \\
\hline Nobs & 40 & 22 & 22 & 326 & 344 & 344 \\
\hline \multicolumn{7}{|c|}{ Yen } \\
\hline & \multicolumn{3}{|c|}{ Interventions } & \multicolumn{3}{|c|}{ No Interventions } \\
\hline & Lead/Lag & Lead & Lag & Lead/Lag & Lead & Lag \\
\hline \multicolumn{7}{|c|}{ Sample: $1978-2002$} \\
\hline $\bar{\beta}$ & -4.945 & -5.694 & -4.413 & -0.584 & -0.745 & -1.485 \\
\hline t-ratio & -4.978 & -4.914 & -4.098 & -1.778 & -2.114 & -2.847 \\
\hline Nobs & 536 & 471 & 472 & 528 & 593 & 592 \\
\hline \multicolumn{7}{|c|}{ Sample: 1978-1993 } \\
\hline $\bar{\beta}$ & -4.707 & -5.762 & -4.020 & -0.379 & -0.316 & -1.412 \\
\hline t-ratio & -4.784 & -4.970 & -3.773 & -1.531 & -1.565 & -2.740 \\
\hline Nobs & 468 & 423 & 424 & 319 & 364 & 363 \\
\hline \multicolumn{7}{|c|}{ Sample: 1993-2002 } \\
\hline $\bar{\beta}$ & -15.149 & -7.657 & -19.675 & 0.730 & -0.791 & -1.128 \\
\hline t-ratio & -1.854 & -0.714 & -2.491 & -0.081 & -0.547 & -0.616 \\
\hline Nobs & 67 & 47 & 48 & 209 & 229 & 228 \\
\hline
\end{tabular}


Table 3: Properties of calibrated models under marginal interventions.

Median and inter-95 percentile range. 5000 replications of weekly observations

\begin{tabular}{|c|c|c|c|c|}
\hline & \multicolumn{2}{|c|}{ U.S.-Germany } & \multicolumn{2}{|c|}{ U.S.-Japan } \\
\hline & UIP & Occasional violation & UIP & Occasional violation \\
\hline \multicolumn{5}{|c|}{$\Delta s_{t+1}=\alpha+\beta r_{t}+\varepsilon_{t+1}$} \\
\hline \multirow[t]{2}{*}{$\beta$} & 1.105 & -2.156 & 1.006 & -3.831 \\
\hline & (0.670: 2.104) & $(-4.02:-1.565)$ & $(0.730: 1.450)$ & $(-5.236:-3.032)$ \\
\hline \multirow[t]{2}{*}{ t-ratio } & 0.399 & -4.156 & 0.039 & -5.814 \\
\hline & $(-1.732: 2.511)$ & $(-5.238:-3.793)$ & $(-2.050: 2.156)$ & $(-6.467:-5.387)$ \\
\hline \multirow[t]{2}{*}{$\mathrm{ARCH}: \chi^{2}(1)$} & 299.27 & 366.26 & 299.97 & 393.378 \\
\hline & (242.74: 352.05$)$ & $(321.61: 405.47)$ & $(251.262: 346.81)$ & (354.70: 428.87) \\
\hline \multicolumn{5}{|c|}{$\operatorname{GARCH}(1,1): h_{t+1}=\omega+\delta \epsilon_{t}^{2}+\gamma h_{t}$} \\
\hline \multirow[t]{2}{*}{$\delta$} & 0.156 & 0.019 & 0.128 & 0.007 \\
\hline & (0.074: 0.288$)$ & (0.008: 0.034$)$ & (0.036: 0.287$)$ & (0.003: 0.018) \\
\hline \multirow[t]{2}{*}{$\gamma$} & 0.834 & 0.977 & 0.833 & 0.991 \\
\hline & (0.724: 0.910$)$ & $(0.942: 0.991)$ & $(0.653: 0.941)$ & $(0.980: 0.996)$ \\
\hline \multicolumn{5}{|c|}{$\underline{h_{t+1}}=a_{0}+a_{1}\left|r_{t}\right|+v_{t}$} \\
\hline \multirow[t]{2}{*}{$a_{1}$} & -423.35 & 634.22 & -114.73 & 108.03 \\
\hline & $(-400.25:-349.32)$ & (445.38: 838.08) & $(-141.99:-87.83)$ & $(-138.22: 369.25)$ \\
\hline \multirow[t]{2}{*}{ t-ratio } & -26.630 & 15.112 & -17.791 & 1.839 \\
\hline & $(-32.755:-20.496)$ & (10.184: 209.385) & $(-22.436:-13.540)$ & $(-2.297: 6.323)$ \\
\hline \multirow[t]{2}{*}{$R^{2}$} & 0.8029 & 0.8316 & 0.829 & 0.848 \\
\hline & (0.759: 0.836$)$ & (0.799: 0.857$)$ & $(0.797: 0.856)$ & $(0.822: 0.868)$ \\
\hline \multicolumn{5}{|c|}{ Exchange Rate } \\
\hline \multirow[t]{2}{*}{$\sigma_{\Delta s}$} & 39.912 & 74.912 & 24.038 & 86.665 \\
\hline & (34.503: 44.675) & (69.858: 79.798) & $(21.825: 26.046)$ & (83.116: 90.372) \\
\hline \multirow[t]{2}{*}{$\rho_{\Delta s}(1)$} & -0.007 & -0.004 & -0.014 & -0.049 \\
\hline & $(-0.072: 0.061)$ & $(-0.070: 0.064)$ & $(-0.081: 0.052)$ & $(-0.107: 0.009)$ \\
\hline \multicolumn{5}{|c|}{ Interest differential } \\
\hline \multirow[t]{2}{*}{$\sigma_{r}$} & 3.088 & 3.088 & 2.973 & 2.973 \\
\hline & (2.270: 3.628$)$ & (2.270: 3.628$)$ & (2.560: 3.278$)$ & (2.560: 3.278$)$ \\
\hline \multirow[t]{2}{*}{$\rho_{r}(1)$} & 0.983 & 0.983 & 0.965 & 0.965 \\
\hline & (0.969: 0.989$)$ & (0.969: 0.989$)$ & $(0.952: 0.973)$ & (0.952: 0.973$)$ \\
\hline \multirow[t]{2}{*}{$\rho_{r}(12)$} & 0.828 & 0.828 & 0.673 & 0.673 \\
\hline & (0.682: 0.896$)$ & $(0.682: 0.896)$ & (0.543: 0.769$)$ & (0.543: 0.769$)$ \\
\hline \multirow[t]{2}{*}{$\rho_{r}(24)$} & 0.688 & 0.688 & 0.453 & 0.453 \\
\hline & (0.447: 0.819$)$ & (0.447: 0.819$)$ & (0.239: 0.629$)$ & (0.239: 0.629$)$ \\
\hline
\end{tabular}

Note: Bold numbers indicate that the data lies outside the inter-95 percentile range. 
Table 4: Properties of calibrated models under inframarginal interventions.

Median and inter-95 percentile range. 5000 replications of weekly observations

\begin{tabular}{|c|c|c|c|c|}
\hline & \multicolumn{2}{|c|}{ U.S.-Germany } & \multicolumn{2}{|c|}{ U.S.-Japan } \\
\hline & UIP & Occasional violation & UIP & Occasional violation \\
\hline \multicolumn{5}{|c|}{$\Delta s_{t+1}=\alpha+\beta r_{t}+\varepsilon_{t+1}$} \\
\hline \multirow[t]{2}{*}{$\beta$} & 1.056 & -1.855 & 1.021 & -2.801 \\
\hline & $(0.396: 2.225)$ & $(-3.644:-0.836)$ & (0.513: 1.696$)$ & $(-4.419:-1.511)$ \\
\hline \multirow[t]{2}{*}{ t-ratio } & 0.114 & -2.853 & 0.060 & -3.735 \\
\hline & $(-1.704: 1.996)$ & $(-4.425:-1.789)$ & $(-1.865: 1.885)$ & $(-5.447:-2.809)$ \\
\hline \multirow[t]{2}{*}{ ARCH: $\chi^{2}(1)$} & 205.98 & 267.55 & 205.22 & 303.54 \\
\hline & (116.11: 331.18$)$ & $(156.23: 147.93)$ & $(121.76: 316.09)$ & (218.55: 389.65) \\
\hline \multicolumn{5}{|c|}{$\operatorname{GARCH}(1,1): h_{t+1}=\omega+\delta \epsilon_{t}^{2}+\gamma h_{t}$} \\
\hline \multirow[t]{2}{*}{$\delta$} & 0.188 & 0.081 & 0.174 & 0.062 \\
\hline & (0.067: 0.379$)$ & (0.034: 0.134$)$ & (0.074: 0.333$)$ & $(0.015: 0.113)$ \\
\hline \multirow[t]{2}{*}{$\gamma$} & 0.712 & 0.891 & 0.666 & 0.892 \\
\hline & $(0.508: 0.875)$ & $(0.843: 0.937)$ & $(0.426: 0.829)$ & (0.833: 0.939) \\
\hline \multicolumn{5}{|c|}{$h_{t+1}=a_{0}+a_{1}\left|r_{t}\right|+v_{t}$} \\
\hline \multirow[t]{2}{*}{$a_{1}$} & 243.12 & 2204 & 77.73 & 1219 \\
\hline & $(-361.20: 778.52)$ & $(731: 4577)$ & $(-76.3279: 189.90)$ & (310: 2213) \\
\hline \multirow[t]{2}{*}{ t-ratio } & 6.56 & 34.06 & 6.74 & 27.81 \\
\hline & $(-18.11: 15.48)$ & (19.16: 56.66) & (-8.60: 12.80) & (9.44: 50.37) \\
\hline \multirow[t]{2}{*}{$R^{2}$} & 0.56 & 0.84 & 0.74 & 0.91 \\
\hline & $(0.43: 0.86)$ & $(0.72: 0.93)$ & $(0.61: 0.90)$ & $(0.85: 0.96)$ \\
\hline \multicolumn{5}{|l|}{ Exchange Rate } \\
\hline \multirow[t]{2}{*}{$\sigma_{\Delta s}$} & 56.31 & 91.73 & 39.402 & 99.492 \\
\hline & (46.44: 72.33$)$ & (74.31: 147.93) & (33.92: 47.12) & $(88.19: 123.60)$ \\
\hline \multirow{2}{*}{$\rho_{\Delta s}(1)$} & -0.006 & -0.036 & -0.009 & -0.049 \\
\hline & $(-0.092: 0.085)$ & $(-0.115: 0.043)$ & $(-0.094: 0.074)$ & $(-0.120: \quad 0.019)$ \\
\hline \multicolumn{5}{|c|}{ Interest differential } \\
\hline \multirow[t]{2}{*}{$\sigma_{r}$} & 3.650 & 3.650 & 3.759 & 3.759 \\
\hline & (2.517: 5.691) & (2.517: 5.691) & (2.888: 5.406$)$ & (2.888: 5.406$)$ \\
\hline \multirow[t]{2}{*}{$\rho_{r}(1)$} & 0.988 & 0.988 & 0.976 & 0.976 \\
\hline & (0.974: 0.995$)$ & (0.974: 0.995$)$ & (0.960: 0.989$)$ & (0.960: 0.989$)$ \\
\hline \multirow[t]{2}{*}{$\rho_{r}(12)$} & 0.868 & 0.868 & 0.766 & 0.766 \\
\hline & (0.723: 0.953$)$ & (0.723: 0.953$)$ & (0.603: 0.891$)$ & (0.603: 0.891$)$ \\
\hline \multirow[t]{2}{*}{$\rho_{r}(24)$} & 0.756 & 0.756 & 0.588 & 0.588 \\
\hline & (0.503: 0.912$)$ & (0.503: 0.912$)$ & (0.329: 0.804$)$ & (0.329: 0.804$)$ \\
\hline
\end{tabular}

Note: Bold numbers indicate that the data lies outside the inter-95 percentile range. 


\section{References}

[1] Alexius, Annika (2001). "Uncovered Interest Parity Revisited," Review of International Economics 3, pp. 505-517.

[2] Baillie, Richard T. and Tim Bollerslev (1994). "The Long Memory of the Forward Premium," Journal of International Money and Finance 13, pp. 565-571.

[3] Baillie, Richard T. and Tim Bollerslev (2000). "The Forward Premium Anomaly Is Not As Bad As You Think," Journal of International Money and Finance 19, pp. 471-488.

[4] Baillie, Richard T. and Tim Bollerslev (1989). 'Common Stochastic Trends in a System of Exchange Rates,' Journal of Finance, 44: 167-181.

[5] Baillie, Richard T. and William P. Osterberg (1997a). "Why Do Central Banks Intervene?" Journal of International Money and Finance 15, pp. 909-919.

[6] Baillie, Richard T. and William P. Osterberg (1997b). "Central Bank Intervention and Risk in the Forward Market," Journal of International Economics 43, pp. 483-497.

[7] Baillie, Richard T. and William P. Osterberg (2000). "Deviations from Daily Uncovered Interest Rate Parity and the Role of Intervention," Journal of International Financial Markets, Institutions and Money 10, pp. 363-379.

[8] Bansal, Ravi and Magnus Dahlquist (2000). 'The Forward Premium Puzzle: Different Tales from Developed and Emerging Economies,' Journal of International Economics, $51,115-144$.

[9] Bertola, Guiseppe and Ricardo J. Caballero (1992). "Target Zones and Realignments," American Economic Review 82, pp. 520-536.

[10] Chaboud, Alain P. and Jonathan Wright (2003). "Uncovered Interest Parity: It Works, But Not For Long," Board of Governors of the Federal Reserve System, International Finance Discussion Papers, Number 752, January.

[11] Chinn, Menzie D. and Guy Meredith (1998). "Long-Horizon Uncovered Interest Rate Parity," National Bureau of Economic Research Working Paper: 6797, November.

[12] Choudhry, Taufiq (1999). "Re-examining Forward Market Efficiency. Evidence from Fractional and Harris-Inder Cointegration Tests," International Review of Economics and Finance 8, pp. 433-453.

[13] Corbae, Dean, Kian-Guan Lim, and Sam Ouliaris (1992). "On Cointegration and Tests of Forward Market Unbiasedness," Review of Economics and Statistics 74, pp. $728-732$. 
[14] Den Haan, Wouter J. and Scott A. Spear (1998). "Volatility Clustering in Real Interest Rates: Theory and Evidence," Journal of Monetary Economics 41, pp. 432-454.

[15] Dominguez, Kathryn M.E. (1998). 'Central Bank Intervention and Exchange Rate Volatility,' Journal of International Money and Finance, 17: 161-190.

[16] Dominguez, Kathryn M. E. (2003). 'The Market Microstructure of Central Bank Intervention,' Journal of International Economics, 59: 25-45.

[17] Duffie, Darrell and Kenneth J. Singleton (1993). "Simulated Moments Estimation of Markov Models of Asset Prices," Econometrica 61, pp. 929-52.

[18] Engel, Charles (1996). "The Forward Discount Anomaly and the Risk Premium: A Survey of Recent Evidence," Journal of Empirical Finance 3, pp. 123-192.

[19] Engle, Robert F. (1982). "Autoregressive Conditional Heteroscedasticity with Estimates of the Variance of United Kingdom Inflation," Econometrica 50, pp. 9871007.

[20] Evans, Martin D.D. and Karen K. Lewis (1995). "Do Long-Term Swings in the Dollar Affect Estimates of the Risk Premia?" Review of Financial Studies 8, pp. 709-742.

[21] Flood, Robert P. and Peter M. Garber (1991). "The Linkage between Speculative Attack and Target Zone Models of Exchange Rates," Quarterly Journal of Economics 106, pp. 1367-1372.

[22] Froot, Kenneth and Richard H. Thaler (1990). "Anomalies: Foreign Exchange," Journal of Economic Perspectives 4, pp. 179-192.

[23] Froot, Kenneth and Jeffrey A. Frankel (1989). "Forward Discount Bias: Is it an Exchange Risk Premium?" Quarterly Journal of Economics 104, pp. 139-161.

[24] Hai, Weike, Nelson C. Mark and Yangru Wu (1997). "Understanding Spot and Forward Exchange Rate Regressions," Journal of Applied Econometrics 12, pp. 715-734.

[25] Hodrick, Robert J. (1987). The Empirical Evidence on the Efficiency of Forward and Futures Foreign Exchange Markets, Chur:Harwood.

[26] Humpage, Owen F. and William P. Osterberg (1992). "Intervention and the foreign exchange risk premium: An empirical investigation of daily effects," Global Finance Journal, 3, 23-50.

[27] Jeanne, Olivier and Andrew K. Rose (2002). 'Noise Trading and Exchange Rate Regimes,' Quarterly Journal of Economics 117, pp. 537-69

[28] Kilian, Lutz and Mark P. Taylor (2002). "Why Is It So Difficult to Beat the Random Walk Forecast of Exchange Rates?" Journal of International Economics, forthcoming. 
[29] Klein, Michael W. and Karen K. Lewis (1993). "Learning about Intervention Target Zones," Journal of International Economics 35, pp. 275-296.

[30] Krugman, Paul R. (1991). "Target Zones and Exchange Rate Dynamics," Quarterly Journal of Economics 106, pp. 669-682.

[31] LeBarron, Blake (1999). "Technical Trading Rule Profitability and Foreign Exchange Intervention," Journal of International Economics, 49, 125-143.

[32] Lee, Bong Soo and Beth Fisher Ingram (1991). "Simulation Estimation of Time-Series Models," Journal of Econometrics 47, pp. 197-205.

[33] Lewis, Karen K. (1995a). 'Puzzles in International Financial Markets.' in Gene Grossman and Kenneth Rogoff eds., Handbook of International Economics, Vol.3, NorthHolland: Amsterdam, pp. 1913-1971.

[34] Lewis, Karen K. (1995b). 'Occasional Interventions to Target Rates,' American Economic Review, 85, pp. 691-715.

[35] Luintel, K.B. and K. Paudyal (1998). "Common Stochastic Trends between Forward and Spot Exchange Rates," Journal of International Money and Finance 17, pp. 279-297.

[36] Mark, Nelson C. and Yangru Wu (1998). "Rethinking Deviations from Uncovered Interest Parity: The Role of Covariance Risk and Noise," Economic Journal 108, pp. $1686-1706$.

[37] McCallum, Bennett T. "A Reconsideration of the Uncovered Interest Parity Relationship," Journal of Monetary Economics 33, 1994, pp. 105-132.

[38] Merton, Robert C. (1990). Continuous-Time Finance, Oxford: Blackwell Publishers.

[39] Michael, Panos, A. Robert Nobay and David A. Peel (1997). "Transactions Costs and Nonlinear Adjustment in Real Exchange Rates: An Empirical Investigation," Journal of Political Economy 105, pp. 862-879.39

[40] Neely, Christopher J. (2002). "The temporal pattern of trading rule returns and exchange rate intervention: intervention does not generate technical trading profits," Journal of International Economics, 58, 211-232.

[41] Stephen Sapp (2004). "Are all Central Bank interventions created equal? An empirical investigation," Journal of Banking \& Finance 28, 443-474.

[42] Schotman, Peter, Stefan Straetmans, and Casper G. de Vries (1997). "Big News in Small Samples," mimeo, Tinbergen Institute, Erasmus University.

[43] Wu, Jyh-Lin and Show-Lin Chen (1998). "Foreign Exchange Market Efficiency Revisited," Journal of International Money and Finance 17, pp. 831-838. 
[44] Zivot, Eric (2000). "Cointegration and Forward and Spot Exchange Rate Regressions," Journal of International Money and Finance 19, pp. 785-812. 


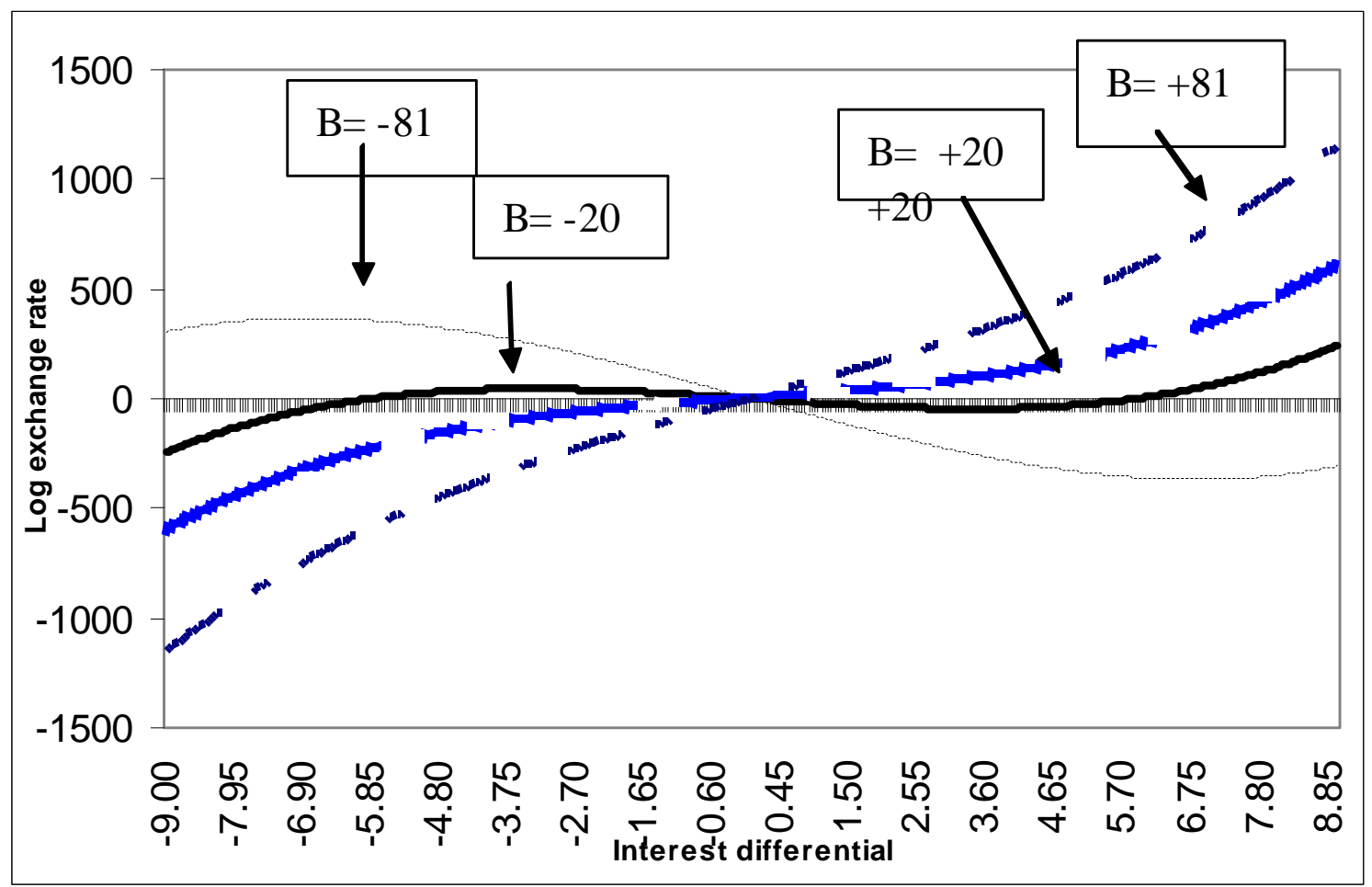

Figure 1: Exchange rate solution under marginal interventions with alternative values of B 


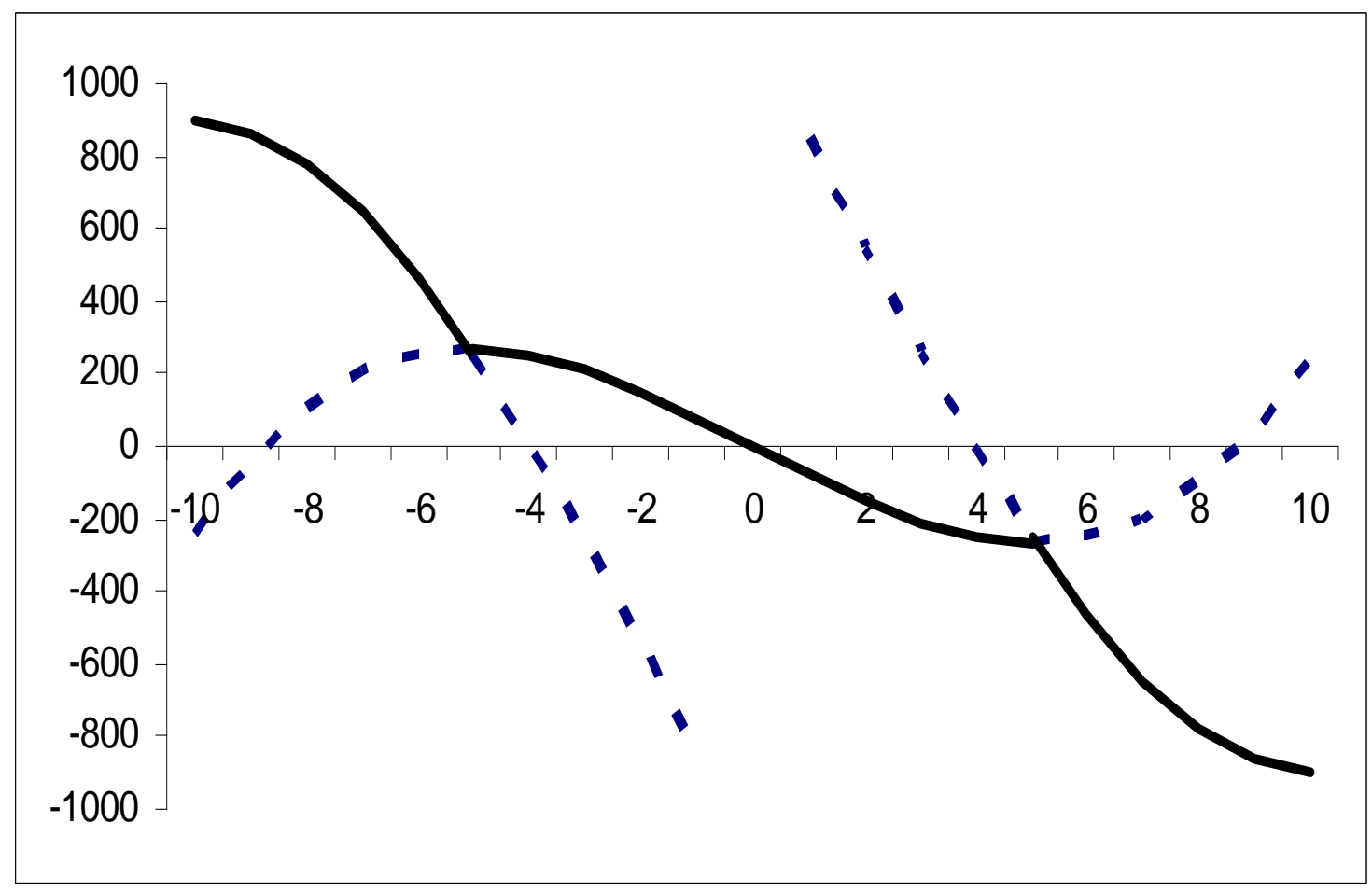

Figure 3. Common-knowledge solution under inframarginal intervention (solid black line) 


\section{Appendix}

\section{A.1 Exchange rate solution}

We first derive the solution under marginal interventions following Krugman's (1992) use of the method of undetermined coefficients. We guess that the solution takes the form,

$$
s(t)=G[r(t)]
$$

where $G(\cdot)$ is a time-invariant continuous and twice differentiable function of $r$. Using Ito's lemma to take the total differential of (A.1) gives

$$
d s(t)=G^{\prime}[r(t)] d r(t)+\frac{1}{2} G^{\prime \prime}[r(t)][d r(t)]^{2},
$$

where $G^{\prime}=d G(r) / d r$ and $G^{\prime \prime}=d^{2} G(r) / d r^{2}$.

Derivation of eq.(3). If the interest differential evolves according to (2), then $d r(t)=$ $\sigma_{r} d z(t)$ and $d r(t)^{2}=\sigma_{r}^{2} d t$. Upon substitution into (A.2), we get

$$
d s(t)=G^{\prime}[r(t)] \sigma_{r} d z(t)+\frac{\sigma_{r}^{2}}{2} G^{\prime \prime}[r(t)] d t .
$$

Now take expectations of both sides of (A.3) conditional on information known at instant $t$

$$
\mathrm{E}_{t}[d s(t)]=\frac{\sigma_{r}^{2}}{2} G^{\prime \prime}[r(t)] d t=r(t) d t,
$$

where the second equality is obtained by UIP. Now we seek to solve the differential equation,

$$
\frac{\sigma_{r}^{2}}{2} G^{\prime \prime}[r(t)]=r(t)
$$

Let the solution to the homogeneous part of (A.4) be $G_{h}$. It must be the case that $G_{h}^{\prime \prime}=0$ which is satisfied by setting $G_{h}=A+B r$. Next, guess that the solution to the nonhomogeneous part is $G_{n}=k r^{3}$. Then $G_{n}^{\prime}=3 k r^{2}, G_{n}^{\prime \prime}=6 k r$. Upon substitution into (A.4), we obtain $k=1 / 3 \sigma_{r}^{2}$. The general solution is therefore $s(t)=G_{h}+G_{n}=A+B r+r^{3} /\left(3 \sigma_{r}^{2}\right)$, which is eq. (3).

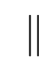

Derivation of restriction $B=-\bar{r}^{2} / \sigma_{r}^{2}$ under the no UIP violations specification. Here, we exploit knowledge of behavior at the bands to determine $B$. Due to the symmetric nature of the bands, we need only examine behavior at one of the bands. Suppose that 
$r(t)$ attains the upper band $\bar{r}$. At that instant, $G^{\prime}[\bar{r}]=0=B+\bar{r}^{2} / \sigma_{r}^{2}$ and solving yields $B=-\left(\bar{r}^{2} / \sigma_{r}^{2}\right)$.

Derivation of $B$ for Flood-Garber interventions. As above, the solution to the nonhomogeneous part of the differential equation is given by $G_{n}=r^{3} /\left(3 \sigma_{r}^{2}\right)$. Writing the guess solution explicitly in terms of the bands gives

$$
G(r \mid \bar{r})=A+\frac{r^{3}}{3 \sigma_{r}^{2}}+B(r-\bar{r})+C(r+\bar{r}) .
$$

Now suppose the upper band is hit at the instant $t_{0}, r\left(t_{0}\right)=\bar{r}$, it follows that

$$
s\left(t_{0}\right)=A+\frac{\bar{r}^{3}}{3 \sigma_{r}^{2}}+2 C \bar{r} .
$$

At the next instant, the interest differential is set to 0 . Since these actions are known with certainty, we have,

$$
s\left(t_{0}+d t\right)=\mathrm{E}_{t} s\left(t_{0}+d t\right)=G(0 \mid \bar{r})=A+(C-B) \bar{r} .
$$

Ruling out arbitrage profits requires that $s\left(t_{0}+d t\right)=s\left(t_{0}\right)$. Thus equating (A.6) and (A.7) gives $(B+C)=-\bar{r}^{2} /\left(3 \sigma_{r}^{2}\right)$. Due to the symmetry of the bands, we have $B=C=$ $-\bar{r}^{2} /\left(6 \sigma_{r}^{2}\right)$. Substituting back into (A.5) gives,

$$
G(r \mid \bar{r})=A-\frac{\bar{r}^{2}}{3 \sigma_{r}^{2}} r+\frac{r^{3}}{3 \sigma_{r}^{2}}
$$

$\|$

Derivation of $B$ for Bertola-Caballero interventions. Again, begin by writing the guess solution explicitly in terms of the bands. The authorities defend with probability $1-p$. If a defense is mounted, the interest differential is reset to 0 . We require $B r=b_{1}(\bar{r}-r)+$ $b_{2}(r-\underline{r})$ which gives $b_{1}=-B / 2, b_{2}=B / 2$. We will write the solution as

$$
G(r \mid \bar{r})=A+C(r-\underline{r})-C(r-\bar{r})+\frac{r^{3}(t)}{3 \sigma_{r}^{2}},
$$

where $C=B / 2$ and $\underline{r}=-\bar{r}$. Now suppose that the upper band $\bar{r}$ is attained at instant $t_{0}$. Then

$$
G(\bar{r} \mid \underline{r}, \bar{r})=A+\frac{\bar{r}^{3}(t)}{3 \sigma_{r}^{2}}+2 C \bar{r}
$$

At the next instant,

$$
s\left(t_{0}+d t\right)=\left\{\begin{array}{c}
G(0 \mid \underline{r}, \bar{r})=A+2 C \bar{r} \quad \text { if defend w.p } 1-p \\
G(2 \bar{r} \mid 3 \bar{r}, \bar{r})=A+\frac{(2 \bar{r})^{3}}{3 \sigma_{r}^{2}} \quad \text { if abandon w.p. } p
\end{array} .\right.
$$


To satisfy the no-arbitrage condition

$$
A+\frac{\bar{r}^{3}}{3 \sigma_{r}^{2}}+2 C \bar{r}=p\left[A+\frac{(2 \bar{r})^{3}}{3 \sigma_{r}^{2}}\right]+(1-p)[A+2 C \bar{r}],
$$

it must be the case that

$$
C=\left(\frac{12 p-1}{2 p}\right)\left(\frac{\bar{r}^{2}}{3 \sigma_{r}^{2}}\right)
$$

$\|$

Derivation of (7). We begin with (4) which, for convenience, we reproduce here as

$$
d s(t)=r(t) d t+\left(B+\frac{r^{2}(t)}{\sigma_{r}^{2}}\right) \sigma_{r} d z(t) .
$$

Integrating gives,

$$
\begin{aligned}
s(1)-s(0) & =\int_{0}^{1} d s(t) \\
& =\underbrace{\int_{0}^{1} r(t) d t}_{(a)}+\underbrace{\frac{1}{\sigma_{r}} \int_{0}^{1} r^{2}(t) d z(t)}_{(b)}+\underbrace{B \sigma_{r} \int_{0}^{1} d z(t)}_{(c)} .
\end{aligned}
$$

Since

$$
r(t)-r(0)=\int_{0}^{t} d r(u)=\sigma_{r} \int_{0}^{t} d z(u)=\sigma_{r}[z(t)-z(0)]
$$

it follows that

$$
(a)=\int_{0}^{1} r(t) d t=r(0)+\sigma_{r} \int_{0}^{1} z(t) d t-\sigma_{r} z(0) .
$$

Next, squaring the interest differential using (A.10) gives

$$
r^{2}(t)=r^{2}(0)+\sigma_{r}^{2}\left[z^{2}(t)+z^{2}(0)-2 z(0) z(t)\right]+2 r(0) \sigma_{r}[z(t)-z(0)]
$$

Integrating (A.11) with respect to $d z(t)$ gives,

$$
\begin{aligned}
(b)=\frac{1}{\sigma_{r}} \int_{0}^{1} r^{2}(t) d z(t)= & \frac{1}{\sigma_{r}}\left\{r^{2}(0) \int_{0}^{1} d z(t)+\sigma_{r}^{2} \int_{0}^{1} z^{2}(t) d z(t)\right. \\
& +\sigma_{r}^{2} z^{2}(0) \int_{0}^{1} d z(t)-2 \sigma_{r}^{2} z(0) \int_{0}^{1} z(t) d z(t) \\
& \left.+2 r(0) \sigma_{r} \int_{0}^{1} z(t) d z(t)-2 r(0) z(0) \sigma_{r} \int_{0}^{1} d z(t)\right\} \\
= & \frac{1}{\sigma_{r}}\left[r(0)-\sigma_{r} z(0)\right]^{2} \int_{0}^{1} d z(t)+2\left[r(0)-\sigma_{r} z(0)\right] \int_{0}^{1} z(t) d z(t) \\
& +\sigma_{r} \int_{0}^{1} z^{2}(t) d z(t) .
\end{aligned}
$$


Now for part (c), we simply note that $B \sigma_{r} \int_{0}^{1} d z(t)=B \sigma_{r}[z(1)-z(0)]$. Substitute these expressions back into (A.9) to get

$$
\begin{aligned}
s(1)-s(0)= & r(0)+\sigma_{r} \int_{0}^{1} z(t) d t-\sigma_{r} z(0)+\frac{1}{\sigma_{r}}\left[r(0)-\sigma_{r} z(0)\right]^{2} \int_{0}^{1} d z(t) \\
& +2\left[r(0)-\sigma_{r} z(0)\right] \int_{0}^{1} z(t) d z(t)+\sigma_{r} \int_{0}^{1} z^{2}(t) d z(t)+B \sigma_{r} \int_{0}^{1} d z(t) \\
\equiv & r(0)+\eta(1)
\end{aligned}
$$

where

$$
\eta(1) \equiv \underbrace{\sigma_{r}\left[\int_{0}^{1} z(t) d t-z(0)\right]}_{(a)}+\underbrace{\frac{1}{\sigma_{r}} \int_{0}^{1} r^{2}(t) d z(t)}_{(b)}+\underbrace{B \sigma_{r} \int_{0}^{1} d z(t)}_{(c)} .
$$

Decomposing $\eta(1)$ into terms that depend on $r(0)$ and those that do not gives $\eta(1)=$ $r(0) \epsilon(1)+v(1)$ where $\epsilon(1)$ is given by (8) and $v(1)$ is given by (9). $\|$

Asymmetric Bands. The symmetric band assumption is not key and can be relaxed. Here, we derive the exchange rate solution when $\underline{r}=-\alpha \bar{r}$. As above, the solution to the nonhomogeneous part of the differential equation is $G_{n}=r^{3} /\left(3 \sigma_{r}^{2}\right)$. We write the general guess solution explicitly in terms as

$$
s(t)=G(r \mid \underline{r}, \bar{r})=A+\frac{r^{3}(t)}{3 \sigma_{r}^{2}}+B[\bar{r}+r(t) / \alpha]+C[\underline{r}+\alpha r(t)] .
$$

At $r(t)=\bar{r}$,

$$
G(\bar{r} \mid \underline{r}, \bar{r})=A+\frac{\bar{r}^{3}(t)}{3 \sigma_{r}^{2}}+B[\bar{r}+\bar{r} / \alpha]
$$

and

$$
G^{\prime}(\bar{r} \mid \underline{r}, \bar{r})=0=B\left[\frac{1+\alpha}{\alpha}\right]+\frac{\bar{r}}{\sigma_{r}^{2}}
$$

which gives

$$
B=-\left[\frac{\alpha}{1+\alpha}\right] \frac{\bar{r}^{2}}{\sigma_{r}^{2}}
$$

Similarly, at $r(t)=\underline{r}$,

$$
G(\underline{r} \mid \underline{r}, \bar{r})=A+\frac{\underline{r}^{3}}{3 \sigma_{r}^{2}}+C[\underline{r}+\alpha \underline{r}]
$$

and

$$
G^{\prime}(\underline{r} \mid \underline{r}, \bar{r})=0=C(1+\alpha)+\frac{\underline{r}^{2}}{\sigma_{r}^{2}}
$$


which gives,

$$
C=-\left[\frac{1}{1+\alpha}\right] \frac{\underline{r}^{2}}{\sigma_{r}^{2}}=-\left[\frac{\alpha^{2}}{1+\alpha}\right] \frac{\bar{r}^{2}}{\sigma_{r}^{2}}=-\alpha B
$$

Inframarginal interventions. We know that the general exchange rate solution is

$$
s=G(r)=A+B r+\frac{r^{3}}{3 \sigma^{2}} .
$$

The hard outer band is $[-\bar{r}, \bar{r}]$ and the inframarginal intervention point is $\bar{r}_{1}$. Looking at the upper bands only:

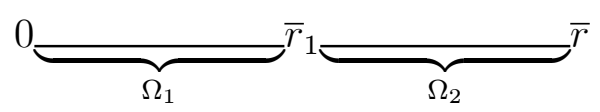

In order to identify the parameters, we model a discrete inframarginal intervention. As $r$ approaches $\bar{r}_{1}$ from below, there is probability $p$ that the bank will intervene. If it does, it will set the interest differential to $\alpha_{1} \bar{r}_{1}$, where $0<\alpha_{1}<1$. If it does not intervene, it will set the interest differential to $\alpha_{2} \bar{r}_{1}$, where $\alpha_{2}>1$

The solution is:

$$
s(t)=\left\{\begin{array}{ll}
G_{1}(r)=A_{1}+B_{1} r+\frac{\alpha_{1}^{3} r^{3}}{3 \sigma^{2}} & \text { if } r \in \Omega_{1} \\
G_{2}(r)=A_{2}+B_{2} r+\frac{\alpha_{2}^{3} r^{3}}{3 \sigma^{2}} & \text { if } r \in \Omega_{2}
\end{array} .\right.
$$

For $r \in \Omega_{1}$, we know we can set $A_{1}=0$ due to symmetry of the intervention rule. At the instant that $\bar{r}_{1}$ is hit, the exchange rate is $s(t)=G_{1}\left(\bar{r}_{1}\right)$. In the next instant,

$$
s(t+d t)=\left\{\begin{array}{l}
G_{1}\left(\alpha_{1} \bar{r}_{1}\right)=B_{1} \alpha_{1} \bar{r}_{1}+\frac{\alpha_{1}^{3} \bar{r}_{1}^{3}}{3 \sigma^{2}} \quad \text { w.p. } p \\
G_{1}\left(\alpha_{2} \bar{r}_{1}\right)=B_{1} \alpha_{2} \bar{r}_{1}+\frac{\alpha_{2}^{3} \bar{r}_{1}^{3}}{3 \sigma^{2}} \quad \text { w.p. } 1-p
\end{array} .\right.
$$

The zero-arbitrage profits condition is that there are no ex ante jumps in the exchange rate, $G_{c}\left(\bar{r}_{1}\right)=p G_{1}\left(\alpha_{1} \bar{r}_{1}\right)+(1-p) G_{1}\left(\alpha_{2} \bar{r}_{1}\right)$ which gives

$$
B_{1}=-\left[\frac{p\left(\alpha_{1}^{3}-\alpha_{2}^{3}\right)-1+\alpha_{2}^{3}}{p\left(\alpha_{1}-\alpha_{2}\right)-1+\alpha_{2}}\right] \frac{\bar{r}_{1}^{2}}{3 \sigma^{2}},
$$

if agents know the rule. If the intervention occurs, the exchange rate continues to be governed by $G_{1}$. If it does not occur, the interest differential passes to region $\Omega_{2}$ where exchange rate is governed by

$$
G_{2}(r)=A_{2}+B_{2} r+\frac{r^{3}}{3 \sigma^{2}}
$$

where

$$
\begin{aligned}
& B_{2}=-\left(\frac{\bar{r}^{2}}{\sigma^{2}}\right), \\
& A_{2}=\left(B_{1}-B_{2}\right) \alpha_{2} \bar{r}_{1}
\end{aligned}
$$


The expression for $B_{2}$ comes from the marginal intervention solution and $A_{2}$ is set in this fashion to glue the exchange rate together to eliminate jumps.

Due to the kink in the exchange rate path, a neutral adjustment (an intervention where UIP holds) needs to occur if re-entering region $\Omega_{1}$ from $\Omega_{2}$. The re-entry intervention is specified as an inframarginal intervention where UIP holds even in the occasional violations specification.

\section{A.2 Simulated method of moments estimation}

Let the simulated observations be denoted with a 'tilde.' For the discretized regulated Brownian motion we divided each of the $T=1200$ weekly time periods into $N=14$ subintervals. Experimentation using $N=7$ and $N=21$ subintervals produced little differences in the results. Setting $\delta_{N}=(1 / N) \simeq d t$, we simulate sequences of (10) by

$$
\tilde{r}_{j}=\tilde{r}_{j-1}+\sigma_{r} \epsilon_{j} \sqrt{\delta_{N}}
$$

where $\epsilon_{j} \stackrel{i i d}{\sim} N(0,1)$ and

$$
\tilde{r}_{j}=\left\{\begin{array}{lll}
\underline{r} & \text { if } & \tilde{r}_{t-1}<\underline{r} \\
\tilde{r}_{j} & \text { if } & \underline{r} \leq \tilde{r}_{j} \leq \bar{r} \\
\bar{r} & \text { if } & \tilde{r}_{t-1}>\bar{r}
\end{array}\right.
$$

for $j=1, \ldots, N M T$. The observations were then re-sampled at weekly intervals giving us a sequence of $M T$ weekly observations (we use $M=30$ ).

SMM estimation of this model proceeds as follows. Let $\beta$ be the vector of parameters to be estimated, $\underline{r}^{\prime}=\left(r_{1}, r_{2}, \ldots, r_{T}\right)$ denote the collection of the actual time-series observations, and $\left\{\tilde{r}_{i}(\beta)\right\}_{i=1}^{M}$ be the computer simulated time-series of length $M$ which we generate according to $(\overline{\mathrm{A}} .19) . \underline{\tilde{r}}^{\prime}(\underline{\beta})=\left(\tilde{r}_{1}(\underline{\beta}), \tilde{r}_{2}(\underline{\beta}), \ldots, \tilde{r}_{M}(\underline{\beta})\right)$ denotes the collection of these $M$ observations. To estimate $\sigma_{r}$ and $\bar{r}$ by matching $\mathrm{E}\left(\overline{\Delta r_{t}}\right), \mathrm{E}\left(\Delta r_{t}\right)^{2}$, and $\mathrm{E}\left(r_{t} r_{t-1}\right)$, we let the vector function of the data from which to simulate the moments be $\underline{h}\left(r_{t}\right)=\left(r_{t}, r_{t}^{2}, r_{t} r_{t-1}\right)^{\prime}$ and the vector of sample moments be $\underline{H}_{T}(\underline{r})=\frac{1}{T} \sum_{t=1}^{T} \underline{h}\left(r_{t}\right)$. The corresponding vector of simulated moments is $\underline{H}_{M}(\underline{\tilde{r}}(\underline{\beta}))=\frac{1}{M} \sum_{i=1}^{M} \underline{h}\left(\tilde{r}_{i}(\underline{\beta})\right)$, where the length of the simulated series is $M$. Now let $\underline{u}_{t}=\underline{h}\left(r_{t}\right)-\underline{H}_{T}(\underline{r})$ be the deviation of $\underline{h}$ from its mean, $\hat{\Omega}_{0}=\frac{1}{T} \sum_{t=1}^{T} \underline{u}_{t} \underline{u}_{t}^{\prime}$ be the sample short-run variance of $\underline{u}_{t}$, and $\hat{\Omega}_{j}=\frac{1}{T} \sum_{t=1}^{T} \underline{u}_{t} \underline{u}_{t-j}^{\prime}$ be the sample cross-covariance matrix of $\underline{u}_{t}, \hat{\mathbf{W}}_{T}=\hat{\mathbf{\Omega}}_{0}+\frac{1}{T} \sum_{j=1}^{m}\left(1-\frac{j+1}{T}\right)\left(\hat{\boldsymbol{\Omega}}_{j}+\hat{\mathbf{\Omega}}_{j}^{\prime}\right)$ is the Newey and West (1987) estimate of the long-run covariance matrix of $\underline{u}_{t}$.

If we let $\underline{g}_{T, M}(\underline{\beta})=\underline{H}_{T}(\underline{r})-\underline{H}_{M}(\underline{\tilde{r}}(\underline{\beta}))$ be the deviation of the sample moments from the simulated moments, then the SMM estimator, $\underline{\beta}_{S}$, is that value of $\underline{\beta}$ that minimizes 
the quadratic distance between the simulated moments and the sample moments

$$
g_{T, M}(\underline{\beta})^{\prime}\left[\mathbf{W}_{T, M}^{-1}\right] g_{T, M}(\underline{\beta}),
$$

where $\mathbf{W}_{T, M}=\left[\left(1+\frac{T}{M}\right) \mathbf{W}_{T}\right]$ and is asymptotically normally distributed with

$$
\sqrt{T}\left(\underline{\hat{\beta}}_{S}-\underline{\beta}\right) \stackrel{D}{\rightarrow} N\left(0, \mathbf{V}_{S}\right)
$$

as $T$ and $M \rightarrow \infty$ where $\mathbf{V}_{S}=\left[\mathbf{B}^{\prime}\left[\left(1+\frac{T}{M}\right) \mathbf{W}\right] \mathbf{B}\right]^{-1}$ and $\mathbf{B}=\frac{\operatorname{E} \partial \underline{\underline{h}}\left[\tilde{q}_{j}(\underline{\beta})\right]}{\partial \underline{\beta}}$.

We estimated $\bar{r}$ and $\sigma_{r}$ by doing a grid search over $\bar{r} \in[2.0,15.0]$ and minimizing with respect to $\sigma_{r}$ for each candidate value of $\bar{r}$. 